\title{
VEGF Inhibitor PTC299
}

National Cancer Institute

\section{Source}

National Cancer Institute. VEGF Inhibitor PT C299. NCI Thesaurus. Code C91100.

An orally bioavailable, small molecule inhibitor of vascular endothelial growth factor (VEGF) synthesis with potential antiang iog enesis and antineoplastic activities. VEGF inhibitor PTC299 targets post-transcriptionally by selectively binding the 5'- and 3'untranslated regions (UTR) of VEGF messenger RNA (mRNA), thereby preventing translation of VEGF. This inhibits VEGF protein production and decreases its levels in the tumor and bloodstream. In turn, this may result in the inhibition of migration, proliferation and survival of endothelial cells, microvessel formation, the inhibition of tumor cell proliferation, and eventually the induction of tumor cell death. VEGFs are upregulated in a variety of tumor cell types and play key roles during angiogenesis. In addition, PT C299 may enhance the antitumor activity of other chemotherapeutic agents. 